\title{
Patient participation in patients with heart failure receiving structured home care - a prospective longitudinal study
}

Lena Näsström ${ }^{1 *}$, Tiny Jaarsma², Ewa Idvall ${ }^{3}$, Kristofer Årestedt $^{4,6}$ and Anna Strömberg ${ }^{5}$

\begin{abstract}
Background: Patient participation is important for improving outcomes, respect for self-determination and legal aspects in care. However, how patients with heart failure view participation and which factors may be associated with participation is not known. The aim of this study was therefore to describe the influence of structured home care on patient participation over time in patients diagnosed with heart failure, and to explore factors associated with participation in care.
\end{abstract}

Methods: The study had a prospective pre-post longitudinal design evaluating the influence of structured home care on participation in patients at four different home care units. Patient participation was measured using 3 scales and 1 single item. Self-care behavior, knowledge, symptoms of depression, socio- demographic and clinical characteristics were measured to explore factors associated with patient participation. Repeated measure ANOVA was used to describe change over time, and stepwise regression analyses were used to explore factors associated with patient participation.

Results: One hundred patients receiving structured heart failure home care were included. Mean age was 82 years, 38 were women and 80 were in New York Heart Association functional class III. One aspect of participation, received information, showed a significant change over time and had increased at both six and twelve months. Better self-care behavior was associated with all four scales measuring different aspects of participation. Experiencing lower degree of symptoms of depression, having better knowledge, being of male sex, being of lower age, cohabiting and having home help services were associated with one or two of the four scales measuring different aspects of participation.

Conclusion: Patients experienced a fairly high level of satisfaction with participation in care at baseline, and there was a significant improvement over time for participation with regard to received information after being admitted to structured home care. Higher level of patient participation was consistently associated with better self-care behavior. This study shows that patient participation may need to be further focused upon, and that the association with self-care may be interesting to target in future interventions.

Keywords: Heart failure, Home care services, Multi-disciplinary care, Patient education, Patient involvement, Patient participation, Self-care, Social support

\footnotetext{
* Correspondence: lena.nasstrom@liu.se

'Department of Medical and Health Sciences, Linköping University, Linköping

58185 , Sweden

Full list of author information is available at the end of the article
} 


\section{Background}

Participation in care is important in order to improve outcomes for patients [1]. It is also vital when it comes to respecting a person's right to self-determination and meeting legal aspects of care $[2,3]$. It is particularly important to promote and facilitate participation in care among patients suffering from chronic illness, such as heart failure (HF) [4,5]. Heart failure is a common condition, and in developed countries the estimated prevalence of symptomatic $\mathrm{HF}$ is $1-2 \%$ of the population $[6,7]$. Heart failure prevalence increases with age and is one of the main causes for hospitalization among people aged 65 years or older, with a substantial risk for rehospitalizations, leading to high medical costs [7]. The organization of HF care has seen many changes in the previous decades, illustrated by the introduction of HF management programs. There has also been a development from inpatient to outpatient care, and care is also to a greater extent provided in the patients' homes $[8,9]$. Previous studies with structured, nurse-led HF home care, have had a positive impact with significantly decreased re-admissions to hospital $[10,11]$, as well as increased survival [11] when compared to follow-up in primary care. However, a more recent study comparing nurse-led care in a home-based setting to a clinic-based setting showed no significant differences between the groups regarding unplanned hospitalizations or death during the 12-18 month follow-up [12]. A considerable part of HF care is already provided in the patients' homes, and from the patient's view home care can be an opportunity to live a more independent life and avoid hospitalizations [13].

\section{Patient participation}

According to the International Classification of Functioning, Disability and Health, participation is "a person's involvement in a life situation", where there is an interaction between activity, participation, health conditions, body functions and structures, and environmental and personal factors [14]. When the concept was analyzed, the findings revealed that participation includes an existing relationship, shared information and knowledge, a will to move power and control to the patient, and mutual activity in intellectual and/or physical activity $[1,15]$. This mutual activity is expected to have positive associations. The concepts of patient participation and involvement can either be synonymous, or to some extent have different meanings [15]. In this paper the concepts are used synonymously. Patient participation includes having knowledge, interaction with health care professionals [16] and decision-making, although the preferences for this differ [17-19]. Patients diagnosed with HF have described participation as having confidence, understanding, seeking and receiving a sense of control [20], or as communication with health care professionals (HCP), accessibility to care, active involvement in care, trustful relations with HCP's and options for decision-making [21]. These findings illustrate that there is no uniform definition of patient participation, and that the concept is complex and includes several different aspects. In addition to previous studies, interventions to increase patient participation have shown that treatment outcomes in diabetes control [22,23], physical activity [24], and adherence to drug treatment in depression [25] improve significantly. Based on previous research, we can assume that there may be a link between patient participation and selfcare, which could be expected to result in improved health outcomes, but other factors probably also influence these outcomes.

\section{Factors associated with patient participation}

Since there is an association between the patient's ability to self-care and management of various aspects of their condition, improving HF self-care is fundamental for improving outcomes [26-28]. By engaging in self-care, patients become active participants [4], and self-care is described as a cognitive process initiated by the patient to maintain health and manage illness and disease [29]. Different aspects of decision-making are involved in selfcare, and these are influenced by interactions between personal characteristics, the problem, and environmental factors [30]. Knowledge is a foundation for HF self-care [31], and being able to apply knowledge about one's condition contributes to patient participation [20]. Patients might find it difficult to understand their symptoms and make a connection to deteriorating HF $[32,33]$, and adhere to a HF regimen [34]. Furthermore, due to typical symptoms and limitations, living with HF influences a person's life, often decreasing the patient's quality of life and reducing functional capacity [7]. Depressive symptoms is also frequent among patients with HF, and up to one third of patients with HF have depressive symptoms $[35,36]$. Patients' preferences for participation could also be influenced by different socio-demographic factors. Studies from other fields have shown that preferences for a higher degree of participation in decision-making are associated with e.g. female sex [37-39], lower age [37,39], higher level of education [38,39], and living alone [38]. On the other hand, other studies have not been able to identify any differences related to sex $[40,41]$ or age [41]. Furthermore, in a review, Hubbard and co-workers [42] state that it has not yet been clarified how socio-demographic factors influence patient participation.

\section{Rationale for the study}

Earlier research indicates that patient participation is of importance, but little is still known of how patients diagnosed with HF view participation, what factors are related 
to patient participation, how patient participation is influenced in specific care settings, and if there is a change in participation over time. In order to understand and improve HF care, it may be of importance to identify a possible association between patient participation, self-care and HF knowledge. We also assume that depressive symptoms may affect patients' ability to participate, as participation includes different aspects of activity, as well as belief in your own ability. However, little is known of how symptoms of depression in patients with HF are associated with patient participation. A better understanding whether socio-demographic factors are associated with patient participation among patients with HF can be useful for improving care. These aspects are of importance in order to improve health outcomes, care, and patient satisfaction with care.

\section{Aim}

The aim of this study was to describe the influence of structured home care on patient participation over time in patients diagnosed with $\mathrm{HF}$, and to explore factors associated with patient participation in care.

\section{Methods}

\section{Design, participants and settings}

The study had a prospective pre-post longitudinal design, evaluating the influence of structured home care on patient participation, with a 12-month follow-up period. Inclusion criteria were patients 18 years or older, and diagnosed with $\mathrm{HF}$ as defined by the European Society of Cardiology [7]. Exclusion criteria were expected survival less than three months, cognitive impairment or mental illness that could affect informed consent or active participation, and difficulties to speak or understand Swedish. A consecutive sample of Swedish patients diagnosed with HF was used. All eligible patients were assessed for study participation at four home care units in Sweden during February 2010 and October 2011. Patients were approached by a study nurse and received both verbal and written information about the study. Two units were situated in a metropolitan area and two in a medium-sized city (about 145000 inhabitants). These units offered home care by a team consisting of a minimum of nurses and physicians, and patients could contact the team at all hours. The team members were specialists in general care as well as being trained in HF and structured home care according to The heart failure at home model [43]. In all units, the HCPs were introduced to the home care model during an educational day at each of the different units, where the components of the model were thoroughly explained. There was also a discussion on how the model could be implemented in clinical practice. The Heart Failure at Home Model consists of six components for home-based management of HF: 1) A multidisciplinary team, minimum physicians and nurses 2) Competencybased staff education 3) Joint care plans and/or care paths 4) Optimized treatment according to guidelines 5) Educational strategies for patients/families/caregivers, and 6) Increased accessibility to care. The model aims to facilitate patient care and focuses on values such as safety, participation and having knowledge about the illness and treatment. Nurses at each unit received additional education in The heart failure at home mode. These nurses were responsible for supporting their colleagues in the implementation of the model. Furthermore, the research team continuously reinforced and followed the process. Through chart reviews and audits, e.g., monitoring of the care plans, access to care and educational strategies, the researchers ensured that the home care model was implemented throughout the study. Structured home care, based on the Heart Failure at Home Model, was given once the patient had completed the baseline questionnaire. All patients received all components of the intervention. The interval of patient contacts (home visits and telephone follow-up) was individualized based on the patient's medical condition and educational needs.

\section{Data collection procedure}

Data were collected at baseline and after 1, 6 and 12 months from patients' self-reports gathered in a questionnaire and from medical records. The questionnaire included demographic questions and a battery of validated instruments to assess participation, self-care behavior, knowledge of HF and symptoms of depression.

\section{Assessment}

\section{Socio-demographic and clinical characteristics}

Data on age, sex, education level, smoking habits and alcohol consumption were collected from patients' selfreports. Data on cohabitation, housing, home help services, New York Heart Association (NYHA) functional classification, hospitalization, mortality, HF medication, blood pressure, pulse rhythm and classification of comorbidities according to the Charlson Co-morbidity Index [44] were collected from medical records. The Charlson Co-morbidity index assign weighted from 1-6 for the presence of specific co-morbidities, with a possible range from $0-34$.

\section{Participation}

To assess aspects of patient views on participation in care, a Swedish questionnaire developed by Arnetz and co-workers was used. The instrument has demonstrated good validity and reliability [45]. In this study, three of the instrument's six scales and one single item were used. These items were selected in collaboration with the instrument developer and were considered applicable to 
patients with HF in a home care context. The first scale, Patient involvement, included six items of how patients define involvement, with a total score of 6-24. The second scale, Information, included five items on received information and explanations regarding medical condition, its course and treatment, with a total score of 5-20. The third scale, Patient needs, included seven items of how needs were fulfilled in terms of asking questions, understanding information and being treated with respect by health care professionals (HCP), with a total score of 7-28. All these items were rated on a four-point Likerttype scale, ranging from don't agree at all (scored 1) to agree completely (scored 4), or from no, not at all (scored 1) to yes, to a great degree (scored 4). Higher scores indicate a more positive rating. Finally, a single item on overall satisfaction with involvement in care was graded on a numeric rating scale, ranging from 1 (not at all satisfied) to 10 (very satisfied). Since the instrument was developed for patients with myocardial infarction (MI) in hospital settings, the wordings in three items were changed slightly in order to adapt them to patients with HF in outpatient care. Cronbach's $\alpha$ values in the three scales used in this study ranged between $0.80-0.88$.

\section{Self-care behavior}

The European Heart Failure Self-care Behavior scale (EHFScB-9) consists of nine statements regarding selfcare in HF and is tested for good validity and reliability [46]. Self-care behavior was estimated on a five-point Likert-type scale, ranging from 1 (completely agree) to 5 (completely disagree). The total score ranged from 9-45. Lower scores indicate better self-care behavior. Cronbach's $\alpha$ was 0.72 in the present study.

\section{Knowledge}

The Dutch Heart Failure Knowledge Scale [47] consists of 15 multiple choice questions about knowledge of HF in general (4 items), HF treatment (6 items) and symptom/symptom recognition (5 items). A score of one was given for each correct answer and zero was given for incorrect answers. The total score ranged from $0-15$. van der Wal and co-workers [47] found the instrument valid and reliable. A translation of the instrument into Swedish has been made, using both forward- and backward translation. To test the instrument's internal consistency in this study, a Kuder Richardson coefficient (KR-20) was calculated (0.54).

\section{Symptoms of depression}

The Patient Health Questionnaire (PHQ-9) [48] with nine items measuring depressive symptoms during the last two weeks was used. PHQ9 has shown to be valid and reliable [49], and has also been validated in patients diagnosed with HF [50]. Each item was rated on a fourgraded scale from not at all to nearly every day, scored from $0-3$ with a total score of $0-27$ points. In the present study, Cronbach's $\alpha$ was 0.80 .

\section{Data analysis}

Descriptive statistics were used to describe the sample and study variables. To make the four scales (patient involvement, information, patient needs and overall satisfaction with involvement in care) comparable, values were calculated by converting the sum to a percentage of the maximum possible score (100\%). This calculation was inspired by the instrument developer [45].

To describe the patients' views of participation at the four measurement points that took place over a 12-month period, a repeated measure ANOVA was performed with the four scales patient involvement, information, patient needs and overall satisfaction with involvement in care [45]. Mauchly's test of sphericity was used to evaluate if the variance in the differences between all possible pairs of groups (i.e., time) were equal. If this assumption was violated, the Huynh-Feldt correction was applied [51].

As a first step to explore factors associated with patients' views of participation, a bivariate correlational analysis was performed, using Spearman's rho correlation coefficient. This analysis was conducted at the first assessment. Variables were selected based on prior empirical evidence or theoretical assumptions hypothesized to be associated with patient participation. In the correlation analysis, the four scales patient involvement, information, patient needs and overall satisfaction were used. Furthermore, symptoms of depression (PHQ-9), selfcare behavior (European Heart Failure Self-Care Behavior Scale), knowledge (Dutch Heart Failure Knowledge Scale), sex, age, cohabitation, housing, home-help services, education level, co-morbidities and NYHA class were included. Based on the results of the bivariate correlation, variables that were to be used as predictors in the regression analysis were determined if the p-value was $<0.10$. In a second step, stepwise linear regression analyses with backward elimination were performed. In these analyses, the four scales patient involvement, information, patient needs and overall satisfaction with involvement in care were used as outcome variables. Based on the findings from the correlation analysis, sociodemographics (age, sex, home-help service and cohabitation), clinical characteristics (NYHA class), knowledge (Dutch Heart Failure Knowledge Scale), symptoms of depression (PHQ-9), and self-care behavior (European Heart Failure Self-Care Behavior Scale), were included to determine predictor variables associated with participation. No variables indicated problems with multicolinarity, the variance inflation factor (VIF) was $<2$ in all models of the 
regression analysis [52]. Except for the Bonferroni corrected post hoc tests, the significance level was set to $<0.05$. Data were analyzed using IBM SPSS Statistics 20.

\section{Ethical considerations}

The study followed the Principles of the Declaration of Helsinki, and participants gave written informed consent. Permission was granted by the Regional Ethical Review Board in Linköping (M210-09).

\section{Results}

\section{Sample and descriptive information}

During the inclusion period 274 patients were eligible, resulting in 100 consecutively included patients at baseline, with 49 patients remaining at the fourth data collection point 12 months later (Figure 1). There were 62 men and the mean age was 82 years. Eighty of the participants were classified in NYHA class III and had a high prevalence of co-morbidities $(4.0 \pm 2.2)$ (Table 1). During the study period, 55 of 100 patients were hospitalized at some point and 42 died. Eighty-seven were prescribed beta-blockers, 95 loop-diuretics and 72 angiotensin -converting enzyme inhibitor/angiotensin receptor blockers. There were no significant differences regarding age and sex between the included patients and those eligible who did not want to participate.

At baseline, patients scored a mean level of $20.7 \pm 6.6$ for self-care behavior (possible range 9-45), and $12.2 \pm$ 2.0 for knowledge of HF (possible range 0-15). Regarding symptoms of depression, patients scored a mean level of $9.5 \pm 6.0$ (possible range $0-27$ ).

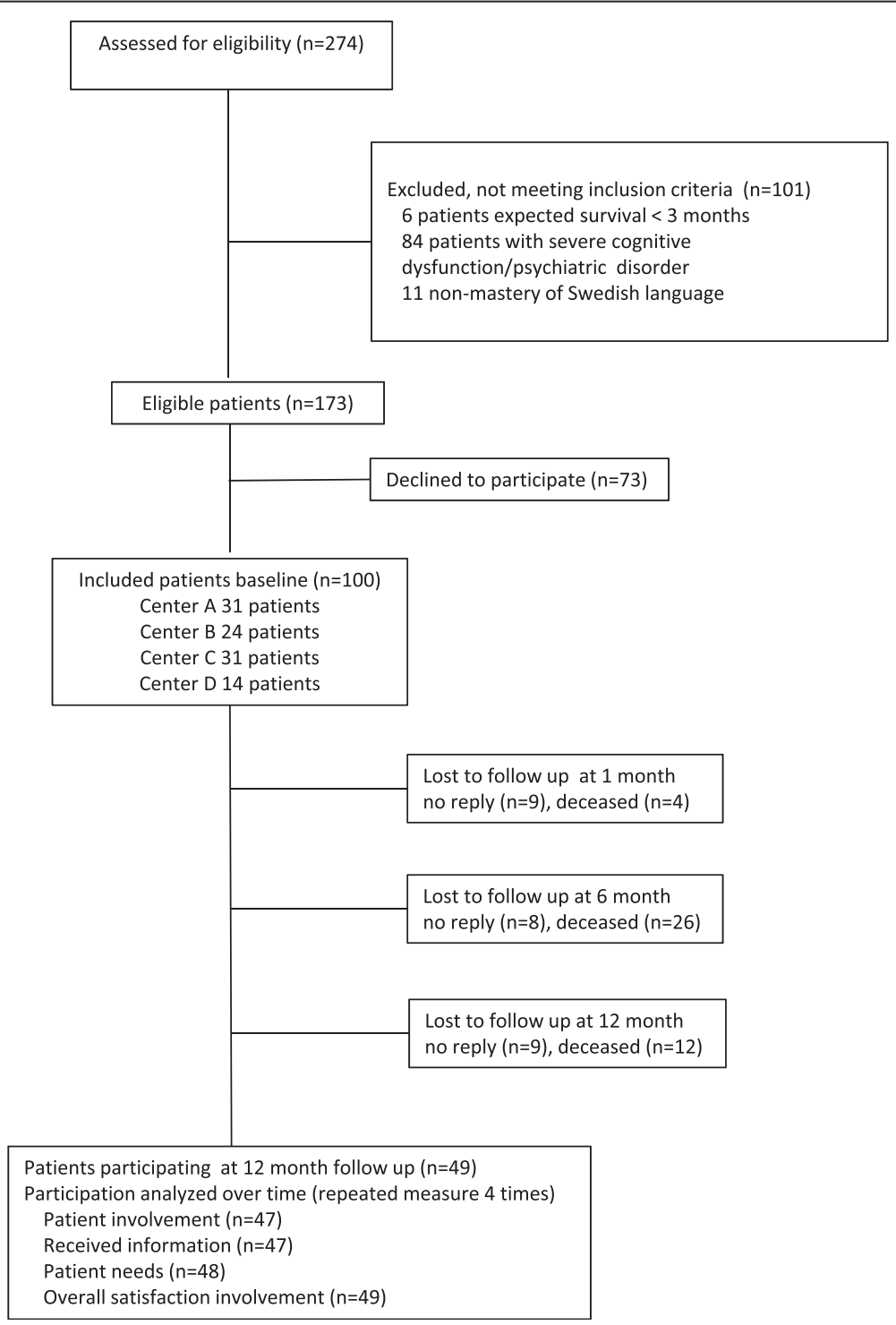

Figure 1 Flow chart of the participants in the study. Study enrollment, follow-up and analysis of different views of participation over time. 
Table 1 Socio-demographic and clinical characteristics of patients at baseline $(n=100)$

\begin{tabular}{|c|c|}
\hline \multicolumn{2}{|l|}{ Socio-demographic and clinical characteristics } \\
\hline Age mean (SD) & $81.7(8.8)$ \\
\hline Male $n$ & 62 \\
\hline Cohabitation $n$ & 52 \\
\hline \multicolumn{2}{|l|}{ Housing $n$} \\
\hline Apartment & 80 \\
\hline Own house & 17 \\
\hline Block of service flats & 3 \\
\hline Home-help service $n$ & 46 \\
\hline \multicolumn{2}{|l|}{ Education level $n$} \\
\hline Elementary, primary and secondary school & 67 \\
\hline High/trade school 2 years & 5 \\
\hline High-school 3-4 years & 10 \\
\hline Higher education/university & 18 \\
\hline \multicolumn{2}{|l|}{ Smoking $n$} \\
\hline Never smoked & 37 \\
\hline Stopped smoking > 1 year ago & 53 \\
\hline Stopped smoking $>1$ month $-<1$ year ago & 2 \\
\hline Smoke regularly & 8 \\
\hline \multicolumn{2}{|l|}{ Alcohol $n$} \\
\hline $1 \leq$ glass/week & 76 \\
\hline 2-7 glasses/week & 20 \\
\hline$>5$ glasses/occasion & 3 \\
\hline missing & 1 \\
\hline \multicolumn{2}{|l|}{ NYHA class $n$} \\
\hline$\|$ & 12 \\
\hline III & 80 \\
\hline IV & 8 \\
\hline $\mathrm{CCl}$ mean (SD) & $4.0(2.2)$ \\
\hline
\end{tabular}

Blood pressure mean (SD)

Systolic

Diastolic

Pulse mean (SD)

Pulse rhythm $n$

regular

irregular

missing

Medication $n$

ACEI/ARB

$\beta$-blockers

87

MRA

Diuretics

Key for abbreviations: NYHA class $=$ New York Heart Association Functional. Classification, $\mathrm{CCl}=$ Charlson Co-morbidity Index, $\mathrm{ACEl}=$ Angiotensin-Converting Enzyme Inhibitors, ARB = Angiotensin Receptor Blocker, $\beta$-Blockers = Beta blockers, $\mathrm{MRA}=$ mineralocorticoid receptor antagonists.

\section{Patient participation over time}

At baseline, patient needs had the highest scores with $23.6 \pm 3.7$ ( $84 \%$ of the max score), followed by patient involvement with $19.5 \pm 3.4$ ( $81 \%$ of the max score), and overall satisfaction with involvement in care with $7.8 \pm$ 1.8 (78\% of the max score). The lowest score was for information with $14.8 \pm 3.4$ ( $74 \%$ of the max score) (Table 2). The mean score of the information scale changed significantly over time, with an increase from $14.8 \pm 3.4$ at baseline to $16.2 \pm 3.0$ at the 12 -month follow-up, indicating higher involvement over time $(\mathrm{p}=0.003)$. The post hoc analysis showed that participation in terms of information increased significantly from baseline to six and twelve months.

\section{Factors associated with participation in care}

The bivariate correlation analysis showed that lower degree of symptoms of depression, better self-care, higher levels of knowledge about HF, male sex, lower age, cohabitation and having home help services were associated with a higher degree of participation, measured by one or more of the four scales $(\mathrm{p}<0.10)$. The scales measuring different aspects of participation correlated significantly with each other $(r=0.22-0.62, \mathrm{p}<0.05)$ (Table 3$)$.

The regression analysis showed that better self-care behavior, living together with someone and younger age were significantly associated with higher-rated importance of involvement $(F(3,92)=13.13, p<0.001)$. These variables explained $30 \%$ of the total variance in this scale (Table 4 ). The degree to which patients stated that they had received information about HF was significantly associated with better self-care behavior, better knowledge about HF, male sex and having home help services $(F(4.91)=$ $9.96, \mathrm{p}<0.001)$. These variables explained $30 \%$ of the total variance in the information scale. Lower degree of symptoms of depression, better self-care behavior and better knowledge about HF was significantly associated with how patients needs were fulfilled with regard to asking questions and being treated with respect by health care professionals $(\mathrm{F}(3,94)=12.14, \mathrm{p}<0.001)$. These variables explained $28 \%$ of the total variance in this scale. Overall satisfaction with involvement in HF care was significantly associated with lower degree of symptoms of depression, better self-care behavior and living together with someone $(\mathrm{F}(4,93)=7.13, \mathrm{p}<0.001)$. NYHA class contributed to the overall fit of the model, although this was not significantly associated with satisfaction of involvement $(\mathrm{p}=0.085)$. These variables explained $24 \%$ of the total variance of the overall satisfaction with involvement in HF care.

\section{Discussion}

This study is the first to explore how patients with HF view participation in structured home care. Our main findings were that although the patients experienced a 
Table 2 Changes in patient participation over time based on a repeated measure ANOVA

\begin{tabular}{|c|c|c|c|c|c|c|c|}
\hline \multirow[t]{3}{*}{ Variable } & \multicolumn{7}{|l|}{ Time } \\
\hline & Baseline (TI) & 1 month (T2) & 6 month (T3) & 12 month (T4) & $F(d f)$ & Main effect over time & Post-hoc ${ }^{a}$ \\
\hline & Mean (SD) & Mean (SD) & Mean (SD) & Mean (SD) & & P-value & \\
\hline Patient involvement $(n=47)$ & $19.53(3.44)$ & $19.28(3.27)$ & $19.43(3.04)$ & $20.21(3.26)$ & $1.997(3)$ & 0.117 & \\
\hline Information ( $n=47)$ & $14.77(3.43)$ & $15.96(2.94)$ & $16.23(3.29)$ & $16.15(2.98)$ & $4.861(3)$ & 0.003 & $\begin{array}{l}B p=0.009 \\
C p=0.008\end{array}$ \\
\hline Patient needs $(n=48)$ & $23.60(3.72)$ & $24.54(3.31)$ & $24.60(3.30)$ & $24.54(3.31)$ & $1.998(2.6)^{\mathrm{b}}$ & $0.126^{\mathrm{b}}$ & \\
\hline $\begin{array}{l}\text { Overall satisfaction involvement } \\
(n=49)\end{array}$ & $7.82(1.80)$ & $7.96(1.64)$ & $7.84(1.88)$ & $7.92(1.64)$ & $0.153(3)$ & 0.928 & \\
\hline
\end{tabular}

Possible score range (a higher score indicates more positive ratings): Patient involvement 6-24; Information 5-20; Patient needs 7-28; Overall satisfaction involvement $1-10$

${ }^{a}=$ Bonferroni corrected $p$-values. Significant differences are reported as $A=T_{1}-T_{2}, B=T_{1}-T_{3}, C=T_{1}-T_{4}, D=T_{2}-T_{3}, E=T_{2}-T_{4}, F=T_{3}-T_{4}$.

${ }^{b}=$ Huynh-Feldt correction according to violation of the assumption of sphericity.

fairly high level of satisfaction with participation in care at baseline, there was a significant improvement over time for participation regarding received information after receiving structured home care. This was encouraging since the structured home care focused on patient education. Furthermore, this is the first study to show that higherrated aspects of patient participation are consistently associated with better self-care behavior in HF.

\section{Different aspects of patient participation and change over time}

We had expected a significant improvement of patient participation with regard to patient involvement, information, patient needs and overall satisfaction with involvement after receiving structured home care. Structured home care had multiple objectives aiming to facilitate the patient's care. The team members had received education about HF and treatment, including the importance of giving structured and individualized information to increase patients' knowledge and self-care. The education did not explicitly focus on how patient participation could be strengthened, and perhaps this is reflected in the result in the present study. However, the aspect of participation with regard to received information increased significantly from baseline to six and twelve months. Patients had received information about their condition, why and how examinations were done and what could happen if their HF deteriorated. This was a significant improvement when receiving structured home care. Findings from qualitative studies with patients suffering from HF

Table 3 Bivariate associations for different factors correlated with the four scales measuring aspects of patient participation at baseline

\begin{tabular}{|c|c|c|c|c|}
\hline Items & Patient involvement & Information & Patient needs & Overall satisfaction involvement \\
\hline \multicolumn{5}{|l|}{ Patient involvement } \\
\hline Information & $0.35^{* *}$ & & & \\
\hline Patient needs & $0.38^{* * *}$ & $0.62^{* * *}$ & & \\
\hline Overall satisfaction involvement & $0.22^{*}$ & $0.32^{* *}$ & $0.49^{* * *}$ & \\
\hline Symptoms of depression & -0.04 & -0.13 & $-0.32^{* *}$ & $-0.34^{* * *}$ \\
\hline Self-care & $-0.38^{* * *}$ & $-0.44^{* * *}$ & $-0.41^{* * *}$ & $-0.29 * *$ \\
\hline Knowledge & $0.19+$ & $0.20^{*}$ & $0.23^{*}$ & 0.11 \\
\hline Co-morbidity & -0.01 & -0.01 & 0.03 & 0.12 \\
\hline NYHA & $0.19+$ & 0.08 & -0.06 & $-0.20+$ \\
\hline Sex & -0.13 & $-0.19+$ & $-0.17 \dagger$ & -0.10 \\
\hline Age & $-0.30^{* *}$ & -0.10 & -0.01 & -0.02 \\
\hline Cohabitation & $0.33^{* *}$ & -0.04 & 0.10 & $0.19+$ \\
\hline Housing & -0.15 & -0.04 & 0.06 & -0.08 \\
\hline Home-help & $-0.23^{*}$ & 0.15 & -0.01 & -0.06 \\
\hline Education & 0.06 & 0.02 & 0.07 & -0.01 \\
\hline
\end{tabular}

${ }^{*} \mathrm{p}<0.05,{ }^{* *} \mathrm{p}<0.01,{ }^{* * *} \mathrm{p}<0.001$.

$\mathrm{tp}<0.10$.

NYHA $=$ New York Heart Association Functional Classification. 
Table 4 Factors associated with participation at baseline, based on stepwise regression with backward elimination

\begin{tabular}{|c|c|c|c|c|}
\hline Outcome variable & Predictor variable & $B(S E)^{a}$ & $95 \% \mathrm{Cl}$ for $\mathrm{B}$ & P-value \\
\hline \multirow[t]{4}{*}{ Patient involvement $(n=96)$} & Self-care & $-0.20(0.05)$ & $-0.30,-0.11$ & $<0.001$ \\
\hline & Cohabiting & $2.17(0.68)$ & $0.82,3.52$ & 0.002 \\
\hline & Age & $-0.08(0.04)$ & $-0.16,-0.01$ & 0.032 \\
\hline & \multicolumn{4}{|c|}{ Model statistics $F(3,92)=13.13, p<0.001, R^{2}=0.30$} \\
\hline \multirow[t]{5}{*}{ Information $(n=96)$} & Self-care & $-0.24(0.05)$ & $-0.33,-0.14$ & $<0.001$ \\
\hline & Knowledge & $0.39(0.16)$ & $0.08,0.70$ & 0.014 \\
\hline & Female sex & $-1.52(0.67)$ & $-2.85,-0.18$ & 0.026 \\
\hline & Having home help & $1.61(0.65)$ & $0.32,2.90$ & 0.015 \\
\hline & \multicolumn{4}{|c|}{ Model statistics $F(4,91)=9.96, p<0.001, R^{2}=0.30$} \\
\hline \multirow[t]{4}{*}{ Patient needs $(n=98)$} & Symptoms depression & $-0.15(0.06)$ & $-0.27,-0.03$ & 0.015 \\
\hline & Self-care & $-0.22(0.05)$ & $-0.33,-0.12$ & $<0.001$ \\
\hline & Knowledge & $0.48(0.17)$ & $0.14,0.82$ & 0.007 \\
\hline & \multicolumn{4}{|c|}{ Model statistics $F(3,94)=12.14, p<0.001, R^{2}=0.28$} \\
\hline Overall satisfaction & Symptoms depression & $-0.09(0.03)$ & $-0.15,-0.02$ & 0.009 \\
\hline \multirow[t]{4}{*}{ involvement $(n=98)$} & Self-care & $-0.08(0.03)$ & $-0.14,-0.03$ & 0.003 \\
\hline & Cohabitation & $1.06(0.37)$ & $0.32,1.79$ & 0.005 \\
\hline & NYHA III-IV & $-1.01(0.58)$ & $-2.17,0.14$ & 0.085 \\
\hline & \multicolumn{4}{|c|}{ Model statistics $F(4,93)=7.13, p<0.001, R 2=0.24$} \\
\hline
\end{tabular}

Key for abbreviation: NYHA class = New York Heart Association Functional Classification.

Self-care; lower numbers indicate better self-care, Knowledge; higher numbers indicate better knowledge, Symptoms of depression; lower numbers indicate less symptoms of depression, Age; lower numbers indicate younger age, Dichotomous variables: Sex $(\mathrm{men}=0$, women $=1)$, Cohabitation $($ No $=0$, Yes $=1)$, Home help (No =0, Yes =1), NYHA (NYHA class II=0, NYHA class III-IV=1).

${ }^{a}$ Unstandardized regression coefficient.

emphasize the importance of an exchange of care-related information to enable participation in care [16,21]. Furthermore, being well-informed contributes to patients' perceived participation $[1,16]$, which is consistent with the results related to received information in this study.

A crucial question that remains unanswered is whether the patients already participated sufficiently in the care. We have no cut-off values in the scales measuring participation, and it is therefore difficult to stipulate what is a good and sufficient outcome for participation. In the Swedish National Patient Survey, participation in relation to care and treatment was scored between 76-81\% within different types of care settings [53]. These results are similar to how patients with HF estimated satisfaction with overall involvement in the present study. Compared to patients hospitalized due to MI [37], the overall satisfaction with involvement was scored lower among patients with HF; $78 \%$ of the maximum score compared to patients with MI who scored $84 \%$. Based on that, the overall satisfaction with involvement in HF home care may have some potential for improvements. Nevertheless, these comparisons between patient groups must be made with caution as they may have been influenced by the patients' characteristics, severity of illness, co-morbidity, age and also the type of care given.
Another question is whether we can expect an increase or change over time in all aspects of participation. For instance, the aspect of patients' definition of the importance of involvement could hypothetically be more stable. Hence, Say and colleagues reported in a review how preferences for participation could change, but there was no clear pattern regarding patients' willingness to participate in decision-making due to the illness experience. In some studies, increased illness experience was associated with increased willingness to participate, while other studies showed the exact opposite results [39], thus illustrating the complexity of drawing conclusions in connection with patients' preferences for participation.

\section{Factors associated with patient participation}

There was a consistent association between the participation scale and self-care behavior. Different aspects of patient participation, such as higher scoring for the definition of the importance of involvement, receiving information, fulfilled needs and higher overall satisfaction with involvement in care were all significantly associated with self-care behavior.

Patient participation includes different aspects, such as making decisions [21], and managing one's condition [20]. Decision-making is an underlying process in self-care, 
where the ability to reflect is of importance for sufficient self-care decisions [4]. Our results showed significant associations between self-care and patient participation. However, based on our results, we cannot exclude that it is participation that affects self-care. Most likely, it is a reciprocal association between self-care and participation.

Knowledge can be seen as a prerequisite to be able to participate in care $[15,54]$. Better knowledge of the HF condition and its symptoms and treatment were associated with higher ratings for received information and fulfilled needs, two of the aspects of patient participation. This confirms earlier findings showing that knowledge gained by obtaining and understanding information has an important role for participation $[1,16]$. Eldh and colleagues reported that patients expressed that having knowledge, which was beyond merely receiving information, was described as participation and led to feelings of being able to manage the situation [16]. From this we can assume that when patients had received information about their condition and also had the opportunity to ask questions related to this information, their knowledge about HF may have been influenced. However, knowledge is a foundation for successful HF self-care [31], but despite increased knowledge, outcomes do not always improve [55]. It may be important to pay attention to patient participation, as we have found a significant association between different aspects of participation and self-care.

From earlier studies it is known that depressive symptoms influence patients' perception of health, their overall life situation [56], and adherence to self-care [57]. Tambuyzer and colleagues described a relationship between patient involvement and patient satisfaction, where involvement predicted patient satisfaction [58]. We also found that a lower degree of depressive symptoms was associated with higher ratings for fulfilled needs and overall satisfaction with involvement in care.

\section{Limitations}

This study has limitations that need to be acknowledged. It was based on a small consecutive sample, and there may also be a selection bias due to the large number of patients who declined to participate. This may affect the generalizability of the results. Overall, the group of patients who received home care for their HF was severely ill and frail. However, it is not uncommon that a high percentage of severely ill patients with HF decline to study participation; this was recently reported by Zambrosky and colleagues [59]. Another limitation was the large number of dropouts between baseline and the 12-month follow-up assessment $(n=51)$. This was partly expected as the sample was in need of home care. To check if our non-significant findings in the ANOVA were the result of lack of statistical power, a post hoc power analysis was conducted using G*Power 3.17. We made a calculation based on a small and a medium effect size for a repeated measure ANOVA, defined by Cohen $(f=0.10$ vs. $f=0.25)[60,61]$. The other parameters for the calculation were a sample size of 47 individuals, $\alpha=$ 0.05 , and four measurement points. From this calculation we identified a power problem in detecting a small effect $(1-B=0.33)$, while the power was sufficiently large to detect a medium effect $(1-B=0.99)$. In addition, the final sample and the dropout did not differ regarding sex and age.

Furthermore, the patients had a mean age of 82 years, which is older than the mean age of the Swedish HF population [62]. The majority of the patients also had severely symptomatic HF classified in NYHA-class III $(80 \%)$ or IV $(8 \%)$, with a relatively high burden of comorbidities. All these circumstances must be taken into consideration when interpreting the results and also affects the generalizability of the results to the whole group of patients diagnosed with HF. With this study design we have examined associations between patient participation and other factors, but this design cannot explain causal relationships. To be able to comment on this, further studies are required. Investigating factors that may mediate or moderate this association could also contribute to a better understanding of the relationship between self-care and participation. This could be done by examining the predictors for change in participation over time, but the sample at the one-year follow-up in the present study was too small for this analysis.

The implementation of The heart failure at home model could also be criticized for being weak as there was only one educational day to introduce the model. This day included education in heart failure and self-care. In selfcare, the patient's involvement is a key factor, which was an important part of the training. In addition, the centers were audited to ensure that the home care model was implemented throughout the study. We realize that we would have needed an RCT to state that this model with structured home care was better than standard homecare, and we can therefore only comment on change with regard to structured home care. However, the study adds to the current knowledge since we particularly studied the HF patients' participation in their care and factors associated with patient participation. This information is valuable when designing future interventions for these severely ill and vulnerable patients.

The measurement properties of the majority of the instruments used in this study had previously been validated. For the present study we also wanted to evaluate the internal consistency of these scales in our sample. However, the Swedish translation of the Dutch Heart Failure Knowledge Scale [47] has not previously been tested for validity and reliability in a Swedish sample. 
To test internal consistency we used KR-20 rather than Cronbach's alpha according to the dichotomous response format. In congruence with the original scale, the Swedish version demonstrated a low KR-20, which could be a limitation. Nonetheless, in some type of instruments all items are not expected to be related to each other. Instead, the items define the construct rather than being defined by it. When this is the case, it may not be relevant to use tests that are based on homogeneity [63], which could be a possible explanation for the low Cronbach's $\alpha$ and KR-20 values related to the knowledge instrument. Another limitation may be that we treated the scales as continuous variables in the regression and ANOVA analyses. The reason was that there is no non-parametric alternative to multiple regression analysis, and therefore we have chosen to take this route during the analyses. The reason why Spearman's correlations were used was that several of the predictor variables were ranked only as categories, i.e. NYHA and educational levels. However, there are divergent views on how this kind of scales should be handled in the analysis stage [64].

\section{Conclusion}

We found that elderly, severely ill patients with HF who had a high prevalence of co-morbidities experienced a fairly high level of satisfaction with participation in structured home care. Patient participation has previously been rarely assessed in patients with HF. Our main findings show that there was a significant improvement over time for participation regarding received information when receiving structured home care. Furthermore, patient participation was consistently associated with self-care behavior. These results need to be investigated further, which may be interesting to target in future interventions aiming at improving self-care.

\section{Abbreviations}

HCP: Health care professionals; HF: Heart failure; MI: Myocardial infarction; NYHA: New York Heart Association.

\section{Competing interests}

The authors declare that they have no competing interests.

\begin{abstract}
Authors' contributions
LN participated in design, carried out the data collection, participated in analysis and interpretation of data, and drafting the manuscript. TJ participated in design, interpretation of data, and drafting the manuscript. El participated in design and drafting the manuscript. KA participated in analysis and interpretation of data, and drafting the manuscript. AS participated in design, analysis and interpretation of data, and drafting the manuscript. All authors have read and approved the final version of the manuscript.
\end{abstract}

\section{Acknowledgement}

The study was funded by the European Commission according to Grant Agreement Homecare 222954, Linköping University, The Swedish Heart and Lung Association, Medical Research Council of Southeast Sweden and the County Council of Östergötland.

\section{Author details}

${ }^{1}$ Department of Medical and Health Sciences, Linköping University, Linköping 581 85, Sweden. ²Department of Social and Welfare studies, Linköping University, Norrköping, Sweden. ${ }^{3}$ Department of Care Science, Malmö University, and Department of Intensive Care and Perioperative Medicine, Skåne University Hospital, Malmö, Sweden. ${ }^{4}$ School of Health and Caring Sciences, Linnaeus University, Kalmar, and Palliative Research Centre, Ersta Sköndal University Collage and Ersta Hospital, Stockholm, Sweden.

${ }^{5}$ Department of Medical and Health Sciences, Linköping University, and Department of Cardiology, County Council of Östergötland, Linköping, Sweden. ${ }^{6}$ Department of Medical and Health Sciences, Linköping University, Linköping, Sweden.

Received: 23 April 2014 Accepted: 3 December 2014

Published online: 18 December 2014

\section{References}

1. Sahlsten MJ, Larsson IE, Sjostrom B, Plos KA: An analysis of the concept of patient participation. Nurs Forum 2008, 43(1):2-11.

2. Patient Self Determination Act of 1990. Available at: http://thomas.loc.gov/ cgi-bin/query/C?c101:/temp/ c101anu0Pk. Accessed December 2, 2013.

3. Ministry of Health and Social Affairs: Health and Medical Services Act 1982:763. In. Available at: http://www.notisum.se/rnp/sls/lag/19820763.htm. Accessed December 2, 2013; 1982.

4. Riegel $B$, Jaarsma $T$, Stromberg A: A middle-range theory of self-care of chronic illness. ANS Adv Nurs Sci 2012, 35(3):194-204.

5. Wagner EH, Austin BT, Davis C, Hindmarsh M, Schaefer J, Bonomi A: Improving chronic illness care: translating evidence into action. Health Aff (Millwood) 2001, 20(6):64-78.

6. Go AS, Mozaffarian D, Roger VL, Benjamin EJ, Berry JD, Borden WB, Bravata DM, Dai S, Ford ES, Fox CS, Franco S, Fullerton HJ, Gillespie C, Hailpern SM, Heit JA, Howard VJ, Huffman MD, Kissela BM, Kittner SJ, Lackland DT, Lichtman JH, Lisabeth LD, Magid D, Marcus GM, Marelli A, Matchar DB, McGuire DK, Mohler ER, Moy CS, Mussolino ME, et al: Heart disease and stroke statistics-2013 update: a report from the American Heart Association. Circulation 2013, 127(1):e6-e245.

7. McMurray JJ, Adamopoulos S, Anker SD, Auricchio A, Bohm M, Dickstein K, Falk V, Filippatos G, Fonseca C, Gomez-Sanchez MA, Jaarsma T, Kober L, Lip GY, Maggioni AP, Parkhomenko A, Pieske BM, Popescu BA, Ronnevik PK, Rutten FH, Schwitter J, Seferovic P, Stepinska J, Trindade PT, Voors AA, Zannad F, Zeiher A, Bax JJ, Baumgartner H, Ceconi C, Dean V, et al: ESC guidelines for the diagnosis and treatment of acute and chronic heart failure 2012: the task force for the diagnosis and treatment of acute and chronic heart failure 2012 of the European society of cardiology. Developed in collaboration with the heart failure association (HFA) of the ESC. Eur J Heart Fail 2012, 14(8):803-869.

8. Genet N, Boerma WG, Kringos DS, Bouman A, Francke AL, Fagerstrom C, Melchiorre MG, Greco C, Deville W: Home care in Europe: a systematic literature review. BMC Health Serv Res 2011, 11:207.

9. Madigan EA: People with heart failure and home health care resource use and outcomes. J Clin Nurs 2008, 17(7B):253-259.

10. Blue L, Lang E, McMurray JJ, Davie AP, McDonagh TA, Murdoch DR, Petrie MC, Connolly E, Norrie J, Round CE, Ford I, Morrison CE: Randomised controlled trial of specialist nurse intervention in heart failure. BMJ 2001, 323(7315):715-718.

11. Stewart S, Horowitz JD: Home-based intervention in congestive heart failure: long-term implications on readmission and survival. Circulation 2002, 105(24):2861-2866.

12. Stewart S, Carrington MJ, Marwick TH, Davidson PM, Macdonald P, Horowitz JD, Krum H, Newton PJ, Reid C, Chan YK, Scuffham PA: Impact of home versus clinic-based management of chronic heart failure: the WHICH? (which heart failure intervention is most cost-effective \& consumer friendly in reducing hospital care) multicenter, randomized trial. J Am Coll Cardiol 2012, 60(14):1239-1248.

13. Whitty JA, Carrington MJ, Stewart S, Holliday J, Marwick TH, Scuffham PA: Patient preferences for the delivery of disease management in chronic heart failure: a qualitative study. J Cardiovasc Nurs 2012, 27(3):201-207.

14. International Classification of Functioning, Disability and Health (ICF) 2001. [http://www.who.int/classifications/icf/en/. Accessed December 2, 2013]. 
15. Cahill J: Patient participation: a concept analysis. J Adv Nurs 1996, 24(3):561-571

16. Eldh AC, Ekman I, Ehnfors M: A comparison of the concept of patient participation and patients' descriptions as related to healthcare definitions. Int J Nurs Terminol Classif 2010, 21(1):21-32

17. Ekdahl AW, Andersson L, Wirehn AB, Friedrichsen M: Are elderly people with co-morbidities involved adequately in medical decision making when hospitalised? A cross-sectional survey. BMC Geriatr 2011, 11:46

18. Sainio C, Eriksson E, Lauri S: Patient participation in decision making about care. Cancer Nurs 2001, 24(3):172-179.

19. Thompson AG: The meaning of patient involvement and participation in health care consultations: a taxonomy. Soc Sci Med 2007, 64(6):1297-1310.

20. Eldh AC, Ehnfors M, Ekman I: The phenomena of participation and non-participation in health care-experiences of patients attending a nurse-led clinic for chronic heart failure. Eur J Cardiovasc Nurs 2004, 3(3):239-246.

21. Nasstrom LM, Idvall EA, Stromberg AE: Heart failure patients' descriptions of participation in structured home care. [published online ahead of print August 21, 2013]. Health Expect 2013. doi:10.1111/hex.12120

22. Greenfield S, Kaplan SH, Ware JE Jr, Yano EM, Frank HJ: Patients' participation in medical care: effects on blood sugar control and quality of life in diabetes. J Gen Intern Med 1988, 3(5):448-457.

23. Rachmani R, Levi Z, Slavachevski I, Avin M, Ravid M: Teaching patients to monitor their risk factors retards the progression of vascular complications in high-risk patients with Type 2 diabetes mellitus-a randomized prospective study. Diabet Med 2002, 19(5):385-392.

24. Arnetz J, Almin K, Bergström Y, Franzen Y, Nilsson $\mathrm{H}$ : Active patient involvement in the establishment of physical therapy goals: effects on treatment outcome and quality of care. Adv Physiother 2004, 6:50-69.

25. Loh A, Leonhart R, Wills CE, Simon D, Harter M: The impact of patient participation on adherence and clinical outcome in primary care of depression. Patient Educ Couns 2007, 65(1):69-78.

26. Evangelista LS, Shinnick MA: What do we know about adherence and self-care? J Cardiovasc Nurs 2008, 23(3):250-257.

27. Lee CS, Moser DK, Lennie TA, Riegel B: Event-free survival in adults with heart failure who engage in self-care management. Heart Lung 2011 40(1):12-20

28. Riegel B, Dickson W: A situation-specific theory of heart failure self-care. J Cardiovasc Nurs 2008, 23(3):190-196.

29. Riegel B, Lee CS, Dickson W: Self care in patients with chronic heart failure. Nat Rev Cardiol 2011, 8(11):644-654.

30. Riegel B, Vaughan Dickson V, Goldberg LR, Deatrick JA: Factors associated with the development of expertise in heart failure self-care. Nurs Res 2007, 56(4):235-243.

31. Stromberg A: The crucial role of patient education in heart failure. Eur J Heart Fail 2005, 7(3):363-369.

32. Carlson B, Riegel B, Moser DK: Self-care abilities of patients with heart failure. Heart Lung 2001, 30(5):351-359.

33. Patel $H$, Shafazand M, Schaufelberger M, Ekman I: Reasons for seeking acute care in chronic heart failure. Eur J Heart Fail 2007, 9(6-7):702-708.

34. van der Wal MH, Jaarsma T, Moser DK, Veeger NJ, Van Gilst WH, Van Veldhuisen DJ: Compliance in heart failure patients: the importance of knowledge and beliefs. Eur Heart J 2006, 27(4):434-440.

35. Adams J, Kuchibhatla M, Christopher EJ, Alexander JD, Clary GL, Cuffe MS, Califf RM, Krishnan RR, O'Connor CM, Jiang W: Association of depression and survival in patients with chronic heart failure over 12 Years. Psychosomatics 2012, 53(4):339-346

36. Eastwood JA, Moser DK, Riegel BJ, Albert NM, Pressler S, Chung ML, Dunbar S, Wu JR, Lennie TA: Commonalities and differences in correlates of depressive symptoms in men and women with heart failure. Eur J Cardiovasc Nurs 2012, 11(3):356-365.

37. Arnetz JE, Arnetz BB: Gender differences in patient perceptions of involvement in myocardial infarction care. Eur J Cardiovasc Nurs 2009, 8(3):174-181.

38. Florin J, Ehrenberg A, Ehnfors M: Clinical decision-making: predictors of patient participation in nursing care. J Clin Nurs 2008, 17(21):2935-2944.

39. Say R, Murtagh M, Thomson R: Patients' preference for involvement in medical decision making: a narrative review. Patient Educ Couns 2006, 60(2):102-114
40. Stewart DE, Abbey SE, Shnek ZM, Irvine J, Grace SL: Gender differences in health information needs and decisional preferences in patients recovering from an acute ischemic coronary event. Psychosom Med 2004, 66(1):42-48.

41. Wilkinson C, Khanji M, Cotter PE, Dunne O, O'Keeffe ST: Preferences of acutely ill patients for participation in medical decision-making. Qual Saf Health Care 2008, 17(2):97-100.

42. Hubbard G, Kidd L, Donaghy E: Preferences for involvement in treatment decision making of patients with cancer: a review of the literature. Eur J Oncol Nurs 2008, 12(4):299-318.

43. Jaarsma T, Strömberg A: HOMECARE. Clinical Continuity by Integrated Care. Grant Agreement No. 222954. A description of EU-criteria/components for optimal based managment of heart failure patients 2010. In. vol. 2013 www.integratedhomecare.eu. Accessed September 13, 2013.

44. Charlson ME, Pompei $\mathrm{P}$, Ales KL, MacKenzie CR: A new method of classifying prognostic comorbidity in longitudinal studies: development and validation. J Chronic Dis 1987, 40(5):373-383.

45. Arnetz JE, Hoglund AT, Arnetz BB, Winblad U: Development and evaluation of a questionnaire for measuring patient views of involvement in myocardial infarction care. Eur J Cardiovasc Nurs 2008, 7(3):229-238.

46. Jaarsma T, Arestedt KF, Martensson J, Dracup K, Stromberg A: The European heart failure self-care behaviour scale revised into a nine-item scale (EHFSCB-9): a reliable and valid international instrument. Eur J Heart Fail 2009, 11(1):99-105.

47. van der Wal MH, Jaarsma T, Moser DK, Van Veldhuisen DJ: Development and testing of the Dutch heart failure knowledge scale. Eur J Cardiovasc Nurs 2005, 4(4):273-277.

48. Spitzer RL, Kroenke K, Williams JB: Validation and utility of a self-report version of PRIME-MD: the PHQ primary care study. Primary care evaluation of mental disorders. Patient health questionnaire. JAMA 1999, 282(18):1737-1744.

49. Kroenke K, Spitzer RL, Williams JB: The PHQ-9: validity of a brief depression severity measure. J Gen Intern Med 2001, 16(9):606-613.

50. Hammash MH, Hall LA, Lennie TA, Heo S, Chung ML, Lee KS, Moser DK: Psychometrics of the PHQ-9 as a measure of depressive symptoms in patients with heart failure. Eur J Cardiovasc Nurs 2013, 12(5):446-453.

51. Weinfurt KP: Repeated measure analysis: ANOVA, MANOVA, and HLM. In Reading and Understanding MORE Multivariate Statistics. Edited by Grimm L, Yarnold PR. Washington, DC: American Psychological Association; 2000:317-361.

52. Miles J, Shevlin M: Applying Regression and Correlation: A Guide for Students and Researchers. Thousand Oaks: Sage Publications Inc; 2001.

53. Swedish Association of Local Authorities and Regions: The National Patient Survey 2012. In. http://npe.skl.se/Default.aspx. Accessed October 21, 2013.

54. Ashworth PD, Longmate MA, Morrison P: Patient participation: its meaning and significance in the context of caring. J Adv Nurs 1992, 17(12):1430-1439.

55. Boyde M, Turner C, Thompson DR, Stewart S: Educational interventions for patients with heart failure: a systematic review of randomized controlled trials. J Cardiovasc Nurs 2011, 26(4):E27-E35.

56. Dekker RL: Patient perspectives about depressive symptoms in heart failure: a review of the qualitative literature. J Cardiovasc Nurs 2014, 29(1):E9-E15.

57. Holzapfel N, Lowe B, Wild B, Schellberg D, Zugck C, Remppis A, Katus HA, Haass M, Rauch B, Junger J, Herzog W, Muller-Tasch T: Self-care and depression in patients with chronic heart failure. Heart Lung 2009, 38(5):392-397.

58. Tambuyzer $E$, Van Audenhove C: Is perceived patient involvement in mental health care associated with satisfaction and empowerment? [published online ahead of print February 21, 2013]. Health Expect 2013. doi:10.1111/hex.12052

59. Zambroski CH, Buck H, Garrison CM, McMillan SC: Lessons from the field: challenges in accruing hospice heart failure patients to intervention research. J Cardiovasc Nurs 2014, 29(1):91-97.

60. Cohen J: Statsitical Power Analysis for the Behavioral Sciences. New York: Academic press; 1977.

61. Cohen J: Statsitical Power Analysis for the Behavioral Sciences. 2nd edition. Hillsdale, NJ: Erlbaum; 1988. 
62. Zarrinkoub R, Wettermark B, Wandell P, Mejhert M, Szulkin R, Ljunggren G, Kahan T: The epidemiology of heart failure, based on data for 2.1 million inhabitants in Sweden. Eur J Heart Fail 2013, 15(9):995-1002.

63. Streiner D, Norman G: Health Measurement Scales a Practical Guide to Development and Use. 3rd edition. Oxford: Oxford University Press; 2003.

64. Knapp TR: Treating ordinal scales as interval scales: an attempt to resolve the controversy. Nurs Res 1990, 39(2):121-123.

doi:10.1186/s12913-014-0633-y

Cite this article as: Näsström et al: Patient participation in patients with heart failure receiving structured home care - a prospective longitudinal study. BMC Health Services Research 2014 14:633.

\section{Submit your next manuscript to BioMed Central and take full advantage of:}

- Convenient online submission

- Thorough peer review

- No space constraints or color figure charges

- Immediate publication on acceptance

- Inclusion in PubMed, CAS, Scopus and Google Scholar

- Research which is freely available for redistribution 